\title{
CARACTERIZAÇÃO DE MARCADORES DE ATIVAÇÃO EM INDIVÍDUOS INFECTADOS PELO Plasmodium vivax
}

\section{CHARACTERIZATION OF ACTIVATION MARKERS IN INDIVIDUALS INFECTED BY Plasmodium vivax}

\author{
Larissa Neuza da Silva Nina ${ }^{1}$; Thayanne França Muniz ${ }^{2}$; \\ Marcos Augusto Grigolim Grisotto ${ }^{3}$
}

RESUMO: A malária é uma doença infecciosa aguda causada por protozoários do gênero Plasmodium e transmitida ao homem pela picada da fêmea do mosquito Anopheles. O P. vivax é uma das 5 espécies que infectam os seres humanos, sendo uma das mais prevalentes na região Amazônica. Este trabalho tem como objetivo analisar marcadores de ativação do sistema imune durante a infecção pelo Plasmodium vivax em infectados residentes na cidade de Cruzeiro do Sul (AC), uma área de transmissão ativa de malária, de modo a se verificar as mudanças que tal infecção provoca no sistema imune. O sangue periférico dos pacientes e controles foi coletado para realização do hemograma e da fenotipagem por citometria de fluxo. Em todos os grupos analisados foi realizado teste de normalidade Shapiro-Wilk nas variáveis numéricas. Foi encontrada uma leucopenia periférica significativa no grupo infectado se comprada ao grupo controle. Quanto a frequência de monócitos e linfócitos totais, não foi encontrada diferença significativa, porém, estudos demonstram que há uma grande ativação de subpopulações de linfócitos. A infecção induziu o aumento de marcadores de ativação (CD69 e HLA-DR) em células T dos indivíduos acometidos pelo Plasmodium vivax. Em conjunto, esses dados sugerem que a infecção pelo $P$. vivax promove ativação de linfócitos T, uma vez que altera significantemente a expressão de marcadores de

\footnotetext{
${ }^{1}$ Acadêmica do curso de Enfermagem da Universidade Ceuma. E-mail: 1.snina.lnina@gmail.com

${ }^{2}$ Enfermeira, Mestre em Biologia Parasitária e Especialista em Urgência e Emergência pela Universidade Ceuma. E-mail: thayanne_muniz@hotmail.com

3 Graduado em Ciências biológicas pela Universidade de São Paulo, graduado em Ciências Biológicas Licenciatura pela Universidade de São Paulo, Graduado em Ciências de Primeiro Grau pela universidade de São Paulo, possui mestrado em Ciências pela Universidade São Paulo, possui Doutorado em Imunologia pela Universidade de São Paulo e Pós-Doutorado no Mount Sinai School of Medicine, NY, USA. Atualmente é Professor/Pesquisador da Universidade Ceuma (MA) e do Instituto Florence de Ensino Superior. E-mail: marcos.grisotto@gmail.com
} 
ativação. Estes resultados apontam para a necessidade gerar informações acerca dos mecanismos imunológicos na malária pelo $P$. vivax que poderão subsidiar $o$ desenvolvimento de futuras pesquisas sobre essa temática e consequentemente novas medidas de intervenção.

PALAVRAS-CHAVE: Plasmodium vivax, Imunologia, marcadores de ativação.

ABSTRACT: Malaria is an acute infectious disease caused by protozoa of the genus Plasmodium and transmitted to humans by the bite of the female mosquito Anopheles. $P$. vivax is one of the five species that infect humans, being one of the most prevalent in the Amazon region. This work aims to analyze the expression of activation markers on leukocytes during Plasmodium vivax infection in patients and controls residents of Cruzeiro do Sul (AC), an area of active transmission of malaria, in order to verify the changes that such infection causes in cells of the immune system. The peripheral blood of the infected subjects was collected for hemogram and immuno-phenotype by flow cytometry. In all groups analyzed, the Shapiro-Wilk normality test was performed on the numerical variables. Significant peripheral leukopenia was found in the infected group compared to the control group. Regarding the frequency of monocytes and total lymphocytes, no significant difference was found, however, studies show that there is a great activation of subpopulations of lymphocytes. The infection induced the increase of activation markers (CD69 and HLA-DR) in T cells of individuals affected by Plasmodium vivax. Together, the data suggest that $P$. vivax infection promotes immunological activation of $\mathrm{T}$ cells, evidenced by higher expression of activation markers. These results are important to understand the role of immune cells and the immunological mechanisms during malaria by $P$. vivax that may support the development of future research on this subject.

KEYWORDS: Plasmodium vivax, Immunology, activation markers. 


\section{INTRODUÇÃO}

A malária é uma das doenças infecciosas mais prevalentes no mundo, acomete milhões de indivíduos por ano, sendo a principal causa de morte e morbidade em diversos países em desenvolvimento, dentre eles o Brasil. A maioria dos casos ocorrem em áreas tropicais e subtropicais. Características epidemiológicas envolvem a fatores determinantes do hospedeiro, porém outros aspectos como tipo de parasita, vetor, condições ambientais e sanitárias influenciam na gravidade da doença (PARENTE et. al. 2012).Além disso, a implementação de políticas sanitárias, econômicas e sociais governamentais estão relacionadas com o sucesso no combate às infecções e na redução do números de casos ao longo dos anos (SIVEP- MALÁRIA, 2012).

A infecção ocorre pela picada da fêmea do mosquito Anopheles cujas glândulas salivares contém protozoários do gênero Plasmodium, havendo 5 espécies que podem infectar seres humanos. No ano de 2013 dos 177.722 casos confirmados de malária no Brasil, $18 \%$ das infecções foram causadas pelo P.falciparum e $82 \%$ pelo $P$. vivax (SIVEP MALÁRIA 2014). Em 2015, foram registrados cerca de 212 milhões de casos de malária no mundo, 126. 211 dos casos correspondiam a infecções pelo $P$. vivax (WHO, 2016). Em 2014, ocorrem no Acre 22\% dos casos notificados na região Amazônica, equivalente a um número de 31.241 infecções (SIVEP MALÁRIA, 2014). Nesse mesmo ano, o estado do Maranhão registrou 1.396 infecções por malária (1\%) (BRASIL, 2014).

O ciclo do parasito inicia-se a partir da picada do mosquito, onde a fêmea inocula os esporozoítos na pele do hospedeiro que caem na corrente sanguínea e invadem os hepatócitos no fígado. Dentro das células hepáticas os esporozoítos se multiplicam e originam milhares de merozoítos (esquizogonia pré-eritrocítica). Os hepatócitos que se encontram infectados se rompem e liberam na corrente sanguínea merozoítos que invadem rapidamente os eritrócitos. O ciclo sanguíneo (esquizogonia eritrocítica) se repete sucessivas vezes, conduzindo à lise de eritrócitos (WHO, 2013). Depois de vários ciclos, alguns parasitas se diferenciam em gametócitos, que são captados pela picada de outra fêmea do mosquito Anopheles, fechando o ciclo do parasita.

O ciclo está diretamente ligado à resposta imunológica da doença, mas a resposta imune frente à malária ainda não é totalmente conhecida. Sabe-se que a 
resposta imune envolve uma complexa apresentação de moléculas com propriedades antigênicas que são responsáveis pela ativação da resposta imune do hospedeiro, o que garante uma resposta diversificada e estágio-específica, atuando assim, contra as diferentes formas evolutivas do parasita. Essa resposta, envolve feedback celular e humoral, onde as células T são essenciais na regulação da produção de anticorpos e na indução da imunidade celular (MIOTO et.al., 2012).

No início da infecção, durante a fase hepática, a resposta imunológica é predominantemente celular, sendo que nesse estágio a redução da densidade parasitária depende da ativação dos linfócitos $\mathrm{T} \mathrm{CD}^{+}$, além de linfócitos $\mathrm{T} C \mathrm{CD} 4^{+}$que são capazes de polarizar a resposta imune para o padrão Th1 (TAYLOR-ROBINSON et al., 1993). Esse mecanismo envolve a produção de citocinas pró-inflamatórias como INF- $\gamma$ pelas células $\mathrm{T}\left(\mathrm{CD}^{+}\right.$e $\left.\mathrm{CD} 8^{+}\right)$que no estágio sanguíneo irão tentar controlar o número de parsitas, o que vai depender do equilíbrio entre as citocinas secretadas pelas células ativadas, já que a severidade da doença tem sido associada com altos níveis sistêmicos de IFN- $\gamma$ e TNF- $\alpha$. A produção de IFN- $\gamma$ pelas células $\mathrm{T}$, ativa macrófagos que vão produzir grandes quantidades de TNF- $\alpha$, responsável pelos paroxismos da malária, podendo contribuir para o aparecimento de sintomas mais graves, como anemia grave e característico da malária cerebral (SCHOFIELD e GRAU, 2005).

Durante a imune garante ocorre grande ativação dos linfócitos T que é medida pelo aumento da expressão de marcadores de ativação celular. Diferentes moléculas são expressas em variados estágios de ativação de linfócitos $\mathrm{T}$, tais como o HLA-DR presente em linfócitos T CD4 ${ }^{+}$e o CD69 que é um marcador expresso por linfócitos T e outros tipos celulares na fase inicial a um estímulo patogênico (LOPES, 2014). A molécula CD69 é um marcador de ativação precoce, estando presente na fase inicial a um estímulo. Essa molécula está envolvida na transmissão dos sinais coestimulatórios, promovencdo a síntese de várias citocinas como IL-2 (interleucina 2), IFN- $\gamma$ e o receptor da interleucina 2 (IL-2R) (TEIXEIRA, 2012; KORNETE et al., 2012).

Tendo em vista que a malária é um grave problema de saúde pública e a escassez de informações a do funcionamento do sistema imunológico durante a infecção, este trabalho tem por objetivo analisar a população de leucócitos totais e a dinâmica de expressão dos marcadores de ativação HLA-DR e CD69 por linfócitos de pacientes infectados pelo $P$. vivax residentes na cidade de Cruzeiro do Sul (AC). 


\section{MATERIAIS E MÉTODOS}

\subsection{POPULAÇÃO ESTUDADA E ASPECTOS ÉTICOS}

Foram analisados 25 indivíduos de ambos sexos (15 homens e 10 mulheres) infectados pelo Plamodium vivax antes do tratamento (fase aguda), residentes em Cruzeiro do Sul (Acre). Participaram também, 10 indivíduos de ambos sexos (homens e mulheres) sadios, que nunca contraíram nenhum tipo de malária, residentes no Estado do Maranhão. Por tratar-se de um estudo que envolve seres humanos a pesquisa foi aprovada pelo Comitê de Ética e Pesquisa da Universidade Ceuma (protocolo 00879/09, de 17/12/2009) e pelo Comitê de Ética da Universidade Federal do Acre (protocolo $136622 / 12)$.

\subsection{CRITÉRIOS DE INCLUSÃO E EXCLUSÃO}

Foram incluídos neste estudo indivíduos acima de 18 anos, de ambos os sexos, com exame de gota espessa positivo para Plasmodium vivax e que concordaram em participar do estudo através da assinatura de um termo de consentimento livre e esclarecido. Foram excluídos do estudo indivíduos com outras co-morbidades ou que faziam uso de esteroides e outros medicamentos que poderiam interferir no curso da doença além de pacientes que se recusaram a participar do estudo.

\subsection{COLETA E ESTOCAGEM DO MATERIAL}

O sangue (cerca de $3 \mathrm{~mL}$ ) dos pacientes e controles foi coletado por punção venosa periférica em tubos contendo heparina, identificado e parte foi separada para confirmação da malária por meio do exame de gota espessa, feito por técnicos treinados e habilitados. Foram coletadas amostras de sangue total.

Todo material foi acondicionado e mantido a $4{ }^{\circ} \mathrm{C}$ por no máximo 6 horas até o processamento laboratorial. As amostras foram encaminhadas para o Centro de Estudos e Pesquisas em Doenças Infeciosas - CEPDI/ Instituto da Biodiversidade/Universidade 
Federal do Acre (UFAC) - Campus Floresta, para serem então utilizadas para realização do hemograma e os experimentos de citometria de fluxo.

\subsection{HEMOGRAMA, SEPARAÇÃO DE PLASMA E ISOLAMENTO DE LEUCÓCITOS COM TAMPÃO DE LISE}

Do total de sangue coletado, cerca de $1 \mathrm{~mL}$ foi utilizado para realização do hemograma com o analisador automático (ABX Micro 60 - HORIBA). Com o restante do sangue, fez-se o isolamento de leucócitos com tampão de lise de hemácias. Após esta etapa as células foram lavados com PBS e as amostras foram centrifugadas. Após o isolamento, as células foram transferidas para uma placa de fundo redondo $\left(1 \times 10^{6}\right.$ células por poço) e marcadas com anticorpos específicos.

\subsection{FENOTIPAGEM DE LEUCÓCITOS POR CITOMETRIA DE FLUXO}

Os leucócitos isolados do sangue periférico foram incubadas com anticorpos anti-CD4, CD8, CD19, CD14, HLA-DR e CD69 marcados com diferentes fluorocromos, todos adquiridos da BD Biosciences Pharmingen. Após a marcação, as células foram captadas utilizando o aparelho de BD Accuri C6 e posteriormente analisadas o software FlowJo (TreeStar, CA)

\subsection{ANÁLISE ESTATÍSTICAS}

Os grupos infectados e controle foram testados quanto a sua distribuição norma pelo teste de normalidade Shapiro-Wilk para variáveis numéricas. Para verificação de diferenças entre dois grupos com distribuição normal foi realizado o Teste $t$ de Student Independente. Para as variáveis sem distribuição normal, a comparação entre os dois grupos foi feita pelo Teste não paramétrico de Mann-Whitney. As diferenças obtidas foram consideradas estatisticamente significativas quando $\mathrm{p}<0,05$. Para apresentação dos dados foram confeccionados gráficos de barras com as médias e Box-plots com medianas dos grupos foi utilizado o programa GraphPad Prism para Windows 5.0 (GraphPad). 


\section{RESULTADOS E DISCUSSÃO}

\subsection{LEUCÓCITOS TOTAIS}

Os leucócitos totais dos indivíduos infectados foram analisados através do hemograma nos grupos controle (C) e infectados (I).

Figura 1: Valores da media de leucócitos totais $\left(10^{3} / \mathrm{mm}^{3}\right)$ no sangue de indivíduos controles (C) e infectados (I) pelo Plasmodium vivax. $* \mathrm{p}<0,05$.

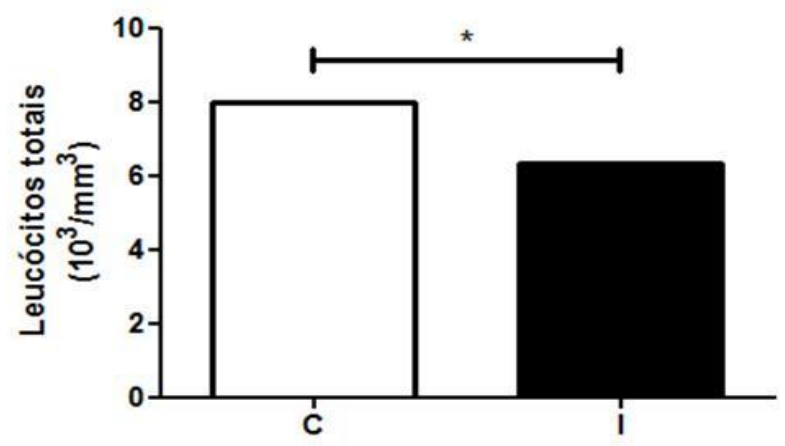

Nos indivíduos infectados pela malária ficou evidenciado uma leucopenia significante durante a fase aguda da doença se comparados com pessoas sadias (Figura 1). Os dados aqui obtidos corroboram com o estudo de Severo (1994), que evidenciou que pacientes com malária podem apresentar leucopenia. Entretanto existem divergências a este respeito na literatura, sendo que alguns estudos também mostram que alterações induzidas pela malária na contagem das células brancas do sangue, que incluem a leucopenia, enquanto que outros autores apontam para leucocitose, havendo certa controvérsia a esse respeito (SANTOS, 2010; WICKRAMASINGHE E ABDALLA, 2000). 


\subsection{POPULAÇÃO DE MONÓCITOS E LINFÓCITOS T $\left(\mathrm{CD} 4^{+} \mathrm{e}\right.$ T CD8 $\left.{ }^{+}\right)$e LINFÓCITOS B}

Figura 2: Valores da media de monócitos (\%) (2A), linfócitos T CD4 ${ }^{+}(\%)$ (2B), linfócitos $\mathrm{T}$ $\mathrm{CD}^{+}(\%)$ (2C) E linfócitos B (2D) em controles (C) e infectados (I) pelo Plasmodium vivax. $* * \mathrm{p}<0,005$.

A

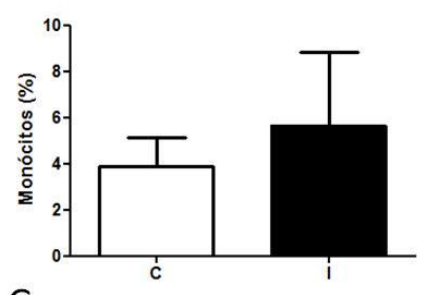

C

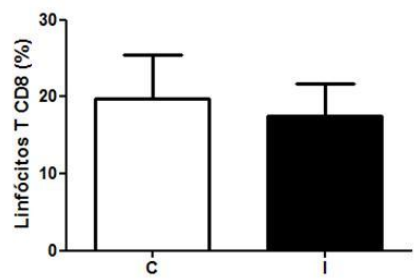

B

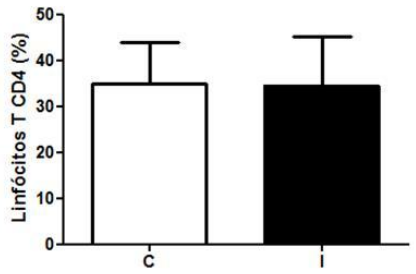

D

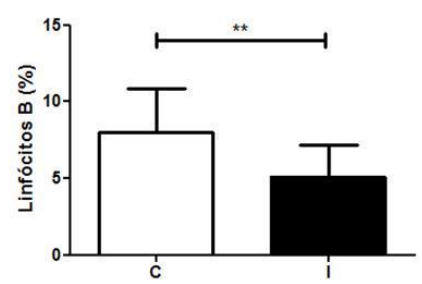

A frequência relativa dos monócitos (Figura 2A), linfócitos T CD4 $4^{+}$(Figura 2B) e de linfócitos $\mathrm{T} \mathrm{CD}^{+}$(Figura $3 \mathrm{C}$ ) não apresentaram diferenças significativas entre os grupos comparados. Por outro lado, verificou-se que a frequência dos linfócitos B diminuiu significativamente nos indivíduos infectados (Figura 2D).

Estudos relatam que apesar da frequência de monócitos e linfócitos totais não se alterarem durante a infecção malárica existe uma grande ativação de subpopulações de leucócitos durante a infecção (KASSA, 2006). Por outro lado, a literatura afirma que os pacientes infectados com malária apresentam diminuição do número absoluto dos linfócitos, gerando assim, uma linfopenia (COSTA, 2013).

Apesar deste estudo não ter demonstrado diferenças significativas na frequência de células $\mathrm{T}$, os linfócitos $\mathrm{T} C \mathrm{CD} 4^{+}$desencadeiam ações como a ativação de macrófagos e monócitos o que irão promover a fagocitose, secreção de citocinas como IL-1 e IL-6 que inibem o desenvolvimento intra-hepático do parasita e contribuindo para ativação de células B e consequente produção de anticorpos (HOFFMAN E FRANKE, 1994; IMAI, 2010).

Em um estudo feito por Tsuji (2010), as células T CD ${ }^{+}$demonstraram papel protetor contra o parasita, especialmente na fase pré-eritrocítica através da destruição de hepatócitos infectados. Costa (2013) observou que a infecção malárica pelo $P$. vivax 
ocasiona um aumento da proporção de células $\mathrm{T} C D 8^{+}$em relação à $\mathrm{TCD} 4^{+}$, o que não foi observado neste estudo.

Neste estudo o grupo de infectados teve diminuição significativa de linfócitos B. Durante a infecção por malária, os linfócitos B são resposnáveis pela resposta imune humoral, ou seja, produzem anticorpos específicos frente ao parasita, importantes para conferir proteção contra as formas sanguíneas do parasita (TAYLOR-ROBINSON, 2010). No entanto, essa persistência de níveis significativos de anticorpos contra a malária baseia-se na exposição contínua à infecção (LANGHORNE et al., 2008).

Estudos afirmam que o número absoluto de linfócitos diminui durante a infecção malárica e tal alteração ocorre pela apoptose induzida em células mononucleares humanas (HVIID et al., 1997; BALDE et al., 2000; XU, 2002). Este fato justificaria a diminuição de linfócitos B nos indivíduos infectados pelo Plasmodium vivax.

\subsection{EXPRESSÃO DE HLA-DR EM MONÓCITOS E LINFÓCITOS T CD4 ${ }^{+}$}

Figura 3: Expressão de HLA-DR por monócitos (A) em indivíduos do grupo controle (C) e infectado (I) pelo Plasmodium vivax. Percentual de células CD14 ${ }^{+} \mathrm{HLA}_{-} \mathrm{DR}^{+}(\mathrm{B})$. Expressão de HLA-DR por células T CD4+ (C) em indivíduos do grupo controle (C) e infectado (I) pelo Plasmodium vivax. Percentual de células $\mathrm{CD}^{+} \mathrm{HLA}^{-D R^{+}}$(D).**p<0,005.

A

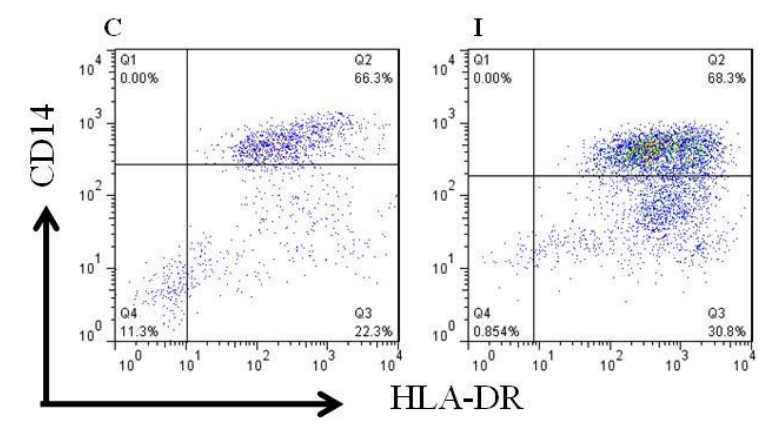

C C
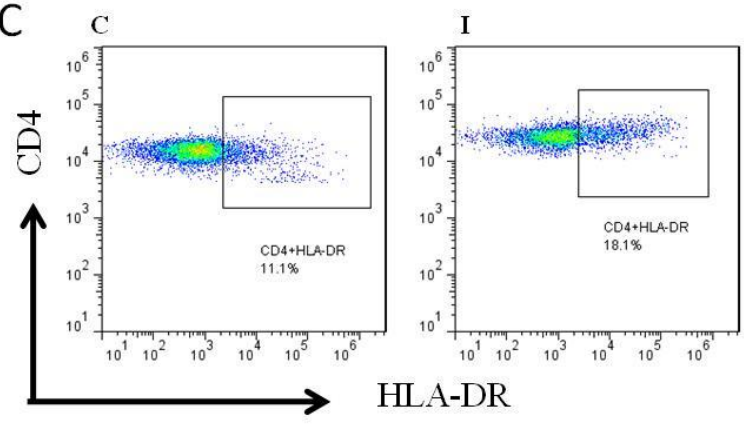

B

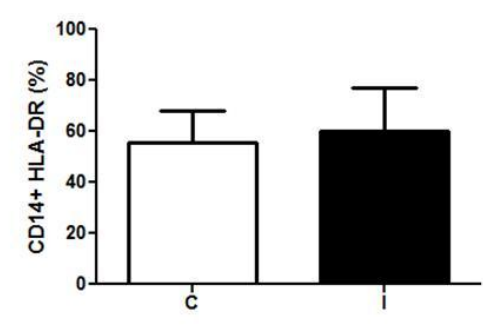

D

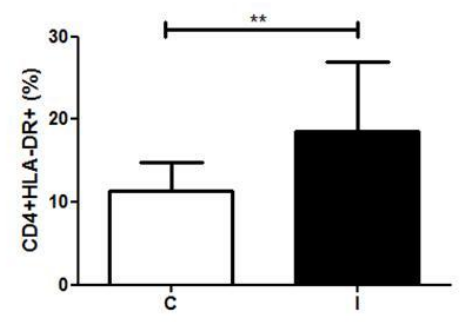

Moléculas de HLA-DR são importantes na geração de respostas imunitárias a micro-organismos, uma vez que a sua principal função em monócitos é apresentar 
peptídeos para ativação e a diferenciação de células T $\mathrm{CD}^{+}$. O aumento de expressão de HLA-DR em monócitos foi estimada do aumento do percentual de células CD14 $^{+}$HLA-DR $^{+}$(Figura 3A). Da mesma forma, a ativação de linfócitos T CD4 ${ }^{+}$foi estimada através da frequência relativa de células T CD4 ${ }^{+} \mathrm{HLA}_{-} \mathrm{DR}^{+}$(Figura 3C) em indivíduos sadios e infectados. Não houve diferença significativa no percentual de células CD14 ${ }^{+} \mathrm{HLA}_{-} \mathrm{DR}^{+}$nos grupos infectados em relação aos controles (Figura 3B). Por outro lado, houve aumento significativo de células T CD $4{ }^{+} \mathrm{HLA}_{-} \mathrm{DR}^{+}$no grupo de infectados em comparação com controles (Figura 3D). Estes achados corroboram com estudos de Taylon-Robinson (1993), onde ficou verificou-se um aumento significativo na expressão de HLA-DR por linfócitos $\mathrm{T}$ e outros tipos celulares em sangue de indivíduos infectados pela malária.

O aumento na expressão e frequência de moléculas de ativação na superfície de linfócitos durante a infecção pelo Plasmodium vivax tem relação com a magnitude da resposta imune frente à infecção malárica, que leva a um recrutamento de células inflamatórias e produção de citocinas a fim de eliminar o patógeno. Estes dados estão em concordância com os dados da literatura que mostram grande ativação do sistema imune em indivíduos infectados pelo Plasmodium, inclusive em gestantes, o que acarreta o aumento da expressão marcadores de ativação como HLA-DR e CD69 em células efetoras (ROETYNCK et al., 2006). 


\subsection{EXPRESSÃO DE CD69 EM LINFÓCITOS $\mathrm{T}\left(\mathrm{CD}^{+} \quad \mathrm{E} \quad \mathrm{CD}^{+}\right) \quad \mathrm{E}$}

\section{LINFÓCITOS B}

Figura 4: Expressão do marcador CD69 em linfócitos T CD4 ${ }^{+}$(A), T CD8 ${ }^{+}$(C) e linfócitos B (E) de indivíduos controles (C) e infectados (I). Percentual de células T CD4 ${ }^{+} \mathrm{CD}^{+} 9^{+}$(B), $\mathrm{T} \mathrm{CD}^{+} \mathrm{CD} 69^{+}$(D) e $\mathrm{CD}_{19}{ }^{+} \mathrm{CD}_{69}{ }^{+}(\mathrm{E})$ em controles e infectados pelo Plasmodium vivax. $* * \mathrm{p}<0,005 ; * * * \mathrm{p}<0,0005$.
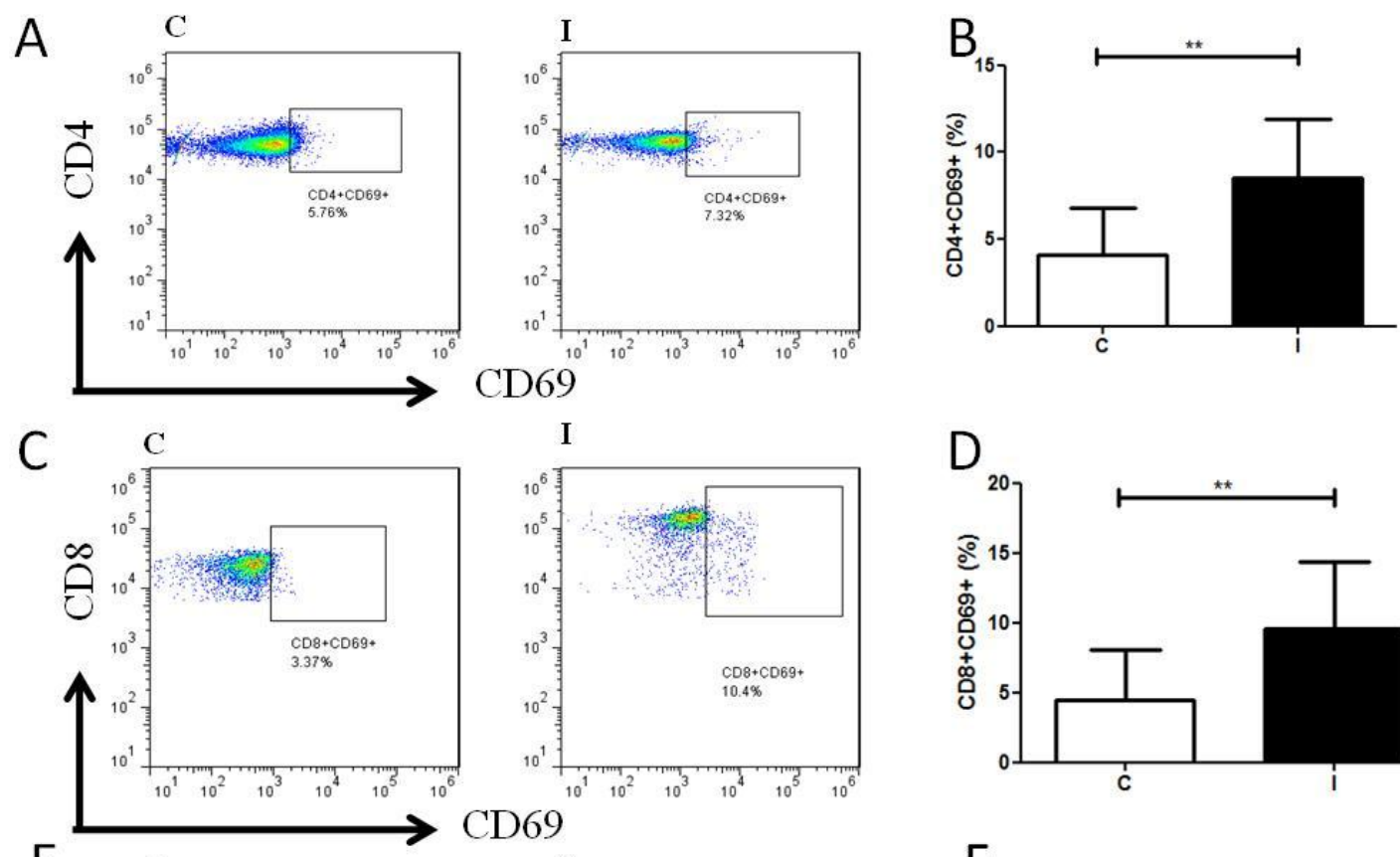

CD69

$\mathrm{E}$
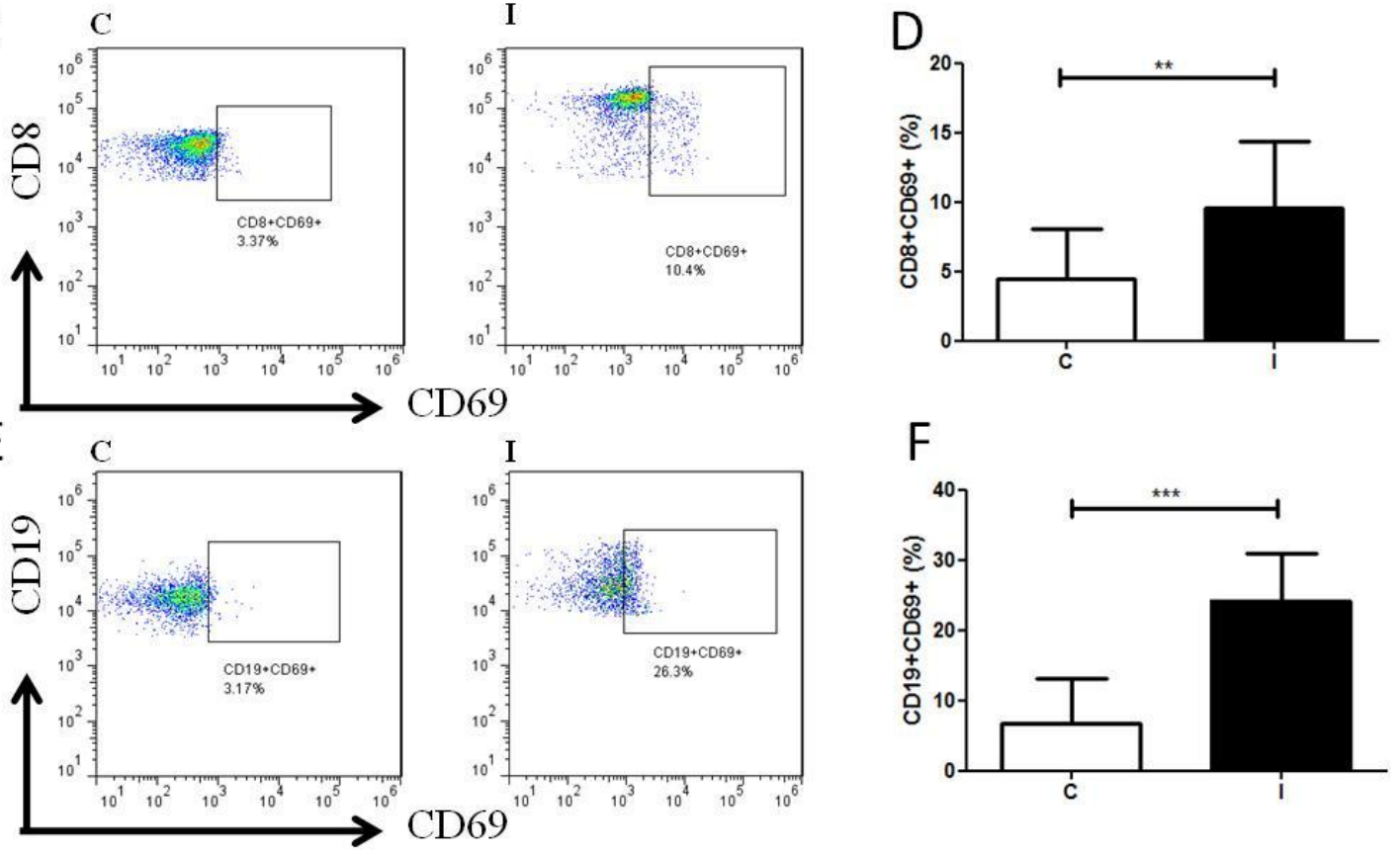

O CD69 é uma molécula expressa em linfócitos na fase inicial de uma exposição a um estímulo, envolvido em uma consequente produção de citocinas. (TEIXEIRA, 2012; KORNETE et al., 2012). Em todas as subpopulações de linfócitos, T CD4 ${ }^{+}$ (Figura 4A-B), linfócitos T CD8 ${ }^{+}$(Figura 4C-D) e linfócitos B (Figura 4E-F) houve aumento significativo de células $\mathrm{CD}^{+} 9^{+}$nos indivíduos infectados em relação aos controles. Em estudo realizado por Lopes (2014), o percentual de linfócitos T CD4 ${ }^{+}$que expressam CD69 também aumentou o que se assemelha com os nossos resultados. 


\section{CONCLUSÕES}

Este trabalho teve como objetivo analisar as alterações fenotípicas nas subpopulações celulares do sangue de pacientes com malária. Foram estudados aspectos hematológicos e imunológicos na infecção pelo Plasmodium vivax em indivíduos residentes em uma área de transmissão ativa (Cruzeiro do Sul- Acre).

Este trabalho evidenciou redução significativa na frequência relativa de células B em pacientes infectados em relação aos controles. Além disso, houve o aumento de marcadores de ativação em linfócitos T e B, como CD69 e HLA-DR em pacientes infectados pelo P. vivax. Com base nesses resultados, podemos perceber que mesmo sem diferença significativa de leucócitos totais o aumento de marcadores de ativação ocorre devido à uma grande ativação destes tipos celulares que têm por objetivo proteção do hospedeiro frente a seu parasito. Esses tipos celulares são importantes na resposta imunológica frente ao parasita, através da produção de citocinas, anticorpos bem como na citotoxicidade frente a hepatócitos infectados. Espera-se que esta pesquisa contribua para o entendimento da dinâmica de expressão destes marcadores durante a infecção bem como estimule mais pesquisas sobre essa temática.

\section{REFERÊNCIAS}

BALDE AT, ARIBOT G, TALL A, SPIEGEL A, ROUSSILHON C. Apoptosis modulation in mononuclear cells recovered from individuals exposed to Plasmodium falciparum infection. Parasite Immunology. v. 22, p. 307-318, 2000.

BRASIL. Ministério da Saúde. Secretaria de Vigilância em Saúde. Serviços de Vigilência Epidemiológica da Malália-SIVEP Malária. Brasília, 2012.

BRASIL. Ministério da Saúde. Secretaria de Vigilância em Saúde. Serviços de Vigilência Epidemiológica da Malália-SIVEP Malária. Brasília, 2014.

COSTA, PAC. Caracterização de moléculas regulatórias durante a malária vivax. 2013. 81f. Tese (Dissertação em Ciências da Biologia Molecular e Celular) - Centro de Pesquisas Renê Rachou.Belo Horizonte, 2013. 
HOFFMAN, SL; FRANKE, ED. Inducing protective imune responses against the esporozoite and liver stages of Plasmodium. Immunology lett. V.41, pp.89-94, 1994.

HVIID, L; KURTZHALS, JA; GOKA, BQ; OLIVER-COMMEY, JO; NKRUMAH, FK; THEANDER, TG. Rapid reemergence of $\mathbf{T}$ cells into peripheral circulation following treatment of severe and uncomplicated Plasmodium falciparum malaria. Infection Immunity. v. 65, p. 4090-4093, 1997.

IMAI, T; SHEN, J; CHOU, B; DUAN, X; TU, L; TETSUTANI, K; MORIYA, C; ISHIDA, H; HAMANO, S; SHIMOKAWA, C; HISAEDA, H; HIMENO, K. Involvement of CD8+ $\mathbf{T}$ cells in protective immunity against murine blood-stage infection with Plasmodium yoelii 17XL strain. Eur J Immunol. v. 40, p. 1053-1061, 2010 .

KASSA, D; PETROS, B; HAILU, E; WOLDAY, D. Characterization of peripheral blood lymphocyte subsets in patients with acute plasmodium falciparum and $\boldsymbol{P}$. vivax malária infection at Wonji Sugar Estate, Ethiopia. Clinical and Vaccine Immunology. V.13, pp. 376-379, 2006.

KHORNETE, M; SGOUROUDIS, E; PICCIRILLO, CA. ICOS dependente homeostasis and funciono f FOXp3 regulatory $T$ cells in islets of nonobese diabetic mice. The joural of immunology. v. 188, p. 1064-1012, 2012.

LANGHORNE, J; NDUNGU, FM; SPONAAS, AM; MARSH K. Immunity to malaria: 40 more questions than answers. Nature Immunology. v. 9, p. 725-732, 2008.

LOPES, RMG. Caracterização de linfócitos T CD4+ que expressam moléculas reguladoras e fontes celulares de interleucina 10 na malária humana. 2014. 142 f. Tese (Doutorado em Ciências) - Instituto de Ciências Biomédicas, universidade São Paulo, São Paulo. 2014.

MIOTO, LD. et al. Aspectos parasitológicos e imunológicos da malária. Biosaúde, Londrina, v.14, n.1, pp. 42-55, 2012. 
PARENTE, AT. et al. A ocorrência de malária em quatro municípios do estado do Pará de 1988 a 2005, e sua redução com o desmatamento. Acta Amazônica, Manaus, v.42, n.1, pp. 41-48, 2012.

Roetynck, S. et al. Natural Killer cells and malária. Immunological Reviews. v.2, n.14, p.251-263, 2006.

SANTOS, VRC dos. Perfil hematológico de uma população de região endêmica na Amazônia. 2010.82f. Tese (Dissertação em Saúde, Sociedade e Endemias da Amazonia).-Universidade Federal do Pará, Belém. 2010.

SCHOFIELD, L; GRAU, GE. Immunological processes in malária pathogenesis. Nature reviews immunology, London, v.5, n.9, pp. 722-735.

SEVERo V, SEVERO, MM, BEHAR PR, DOSSIN TJ. Perfil laboratorial do paciente malárico. Revista da Sociedade Brasileira de Medicina Tropical, v.4, pp. 141154, 1994.

TAYLOR-ROBINSON, AW; PHILLIPS, RS; SEVERN, A; MONCADA, S; LIEW, FY. The role of Th1 and Th2 cells in a rodent malaria infection. Science. vol. 260, p. 1931-1934, 1993.

TAYLOR-ROBINSON, AW. Regulation of immunity to Plasmodium: implications from mouse models for blood stage malaria vaccine design. Experimental Parasitology. v. 126, p. 406-414, 2010.

TEIXEIRA FC. Marcadores de ativação de linfócitos $\mathbf{T}$ e suas citocinas como ferramentas de diagnósticas na hipersensibilidade alérgica a fármacos. $2012.110 \mathrm{f}$. Universidade Federal do Ceará, Fortaleza. 2012.

TSUJI MA. Retrospective evaluation of the role of $\mathbf{T}$ cells in the development of malaria vaccine. Exp Parasitol. v.126, p. 421-425, 2010.

XU, H; WIPASA, J; YAN, H; ZENG, M; MAKOBONGO, MO; FINKELMAN, FD; et al. The mechanism and significance of deletion of parasite-specific CD4(+) $T$ cells in malaria infection. Journal Experimental Medicine. vol. 195, p. 881-892, 2002. 
Revista Ceuma Perspectivas, Edição Especial. V Congresso de Saúde e Bem Estar Ceuma. Vol. 30, nº2, 2017.
ISSN Eletrônico: 2525-5576.

WICKRAMASINGHE, SN; ADALLA, SH. Blood amd boné marrow changes in malária. Baillieres Best Practice \& Research Clinical Haematology. V.13, p.227-299, 2000.

WORLD HEALTH ORGANIZATION (WHO). Monitoring Antimalarial Drug Resistance. WHO/CDS/CSR/EPH/. Geneva. 2016. 